UDK: 72.01:004.42

DOI: https://doi.org/10.24867/03FA01Sucevic

\title{
VIZUALIZACIJA URBANOG PODRUČJA - STUDIJA SLUČAJA NOVA LUKA U KOPENHAGENU
}

\section{VISUALIZATION OF THE URBAN AREA - CASE STUDY NYHAVN, COPENHAGEN}

\author{
Iva Sučević, Fakultet tehničkih nauka, Novi Sad
}

\section{Oblast - ARHITEKTONSKA VIZUALIZACIJA}

Kratak sadržaj - Vizualizacija se danas sve više koristi za predstavljanje prostora, kako u filmskoj $i$ gaming (gejming) industriji, tako $i$ u arhitekturi, za reprezentaciju enterijera i eksterijera. Kod arhitektonske vizualizacije od ključne je važnosti postizanje kvaliteta rendera takvog da prikazani prostor deluje realno. To se postiže kroz analiziranje fotografija postojećeg prostora $i$ prilagođavanjem karakteristika rendera rezultatima tih analiza.

Ključne reči: Arhitektura, vizualizacija, 3D, modelovanje Abstract - Visualization is increasingly being used today to represent space, both in film and gaming industry, as well as in architecture, for representation of interior and exterior. In architectural visualization, it is essential to achieve the quality of the rendered image that represents the real world. This is achieved by analyzing photographs of existing enviroment and adapting the rendering characteristics according to the results of these analyzes.

Keywords: Architecture, visualization, 3D, modelling

\section{UVOD}

Cilj ovog rada je vizualizovati prostor eksterijera urbanog područja u različito doba dana i sa različitim vremenskim uslovima. Odabrani prostor ima karakterističnu arhitekturu, sadrži vodu i prikazuje efekat gužve. Vremense promene utiču na ambijent i boje fasada, što će biti prikazano kroz karakterističnu arhitekturu.

Prisustvo vode dodatno pojačava uticaj promene atmosfere i efekat koji ona ima na ambijent, a efekat gužve obogaćuje scenu. Prvi korak ka dobrom realizmu u arhitektonskim vizualizacijama je dobro postavljanje i dimenzionisanje modela. To se odnosi na, pre svega, konkretno postavljenu perspektivu i pozicioniranje objekta u odnosu na kameru. sledeći korak jeste pozicioniranje svetla i određivanje njegovog inteziteta. Kao poslednji korak postavljaju se materijali.

Nakon kraće obrade $\mathrm{u}$ postprodukciji nastaje render koji treba da izgleda što sličnije referentnoj fotografiji. Trenutna metoda, kod koje se koriste dodatne fotografije i kamere iz novih uglova, sa novim perspektivnim projekcijama, povećava potrebno vreme za izradu modela. Problem kojim će se ovaj rad baviti jeste dobro postavljanje geometrije visoke detaljnosti u odnosu na samo jednu fotografiju.

\section{NAPOMENA :}

Ovaj rad proistekao je iz master rada čiji mentor je bila doc. dr Vesna Stojaković.

\section{ODABIR REFERENTNE FOTOGRAFIJE}

\subsection{Kriterijumi za odabir referentne fotografije}

Odabrano je nekoliko fotografija iz istog ili sličnog ugla sa različitom atmosferom u različito doba dana. Korišćene su slike različitog kvaliteta, u cilju prikazivanja uticaja geometrije na render bez obzira na vrstu osvetljenja. Prvi kriterijum za odabir referentne fotografije jeste taj da konkretna pozicija odakle je fotografija slikana mora biti prometna. To daje potencijalno veliku bazu fotografija. Drugi kriterijum izbora fotografije jeste godišnje doba. Pošto je fokus ovog rada na geometriji i uticaju svetla na istu potrebno je pronaći što jasnije fotografije, odnosno one bez smetnji usled kiše i snega. Treći kriterijum za odabir fotografija je da one nisu prošle kroz veliki broj promena u postprodukciji.

\subsection{Karakteristike prostora}

Odabrana lokacija za analizu slika i vizualizaciju eksterijera je poznata luka Nayhavn, u Kopenhagenu, u Danskoj. Analiza će biti izvršena prema fotografijama koje su uslikane iz određenog ugla posmatranja - pogled ka kućama u nizu na „sunčanoj strani”. Taj deo se nalazi na Severnoj strani kanala. Fotografije su slikane sa mosta koji je frekventan, u različito doba dana i pri različitim vremenskim uslovima. Biće analizirani i vizualizovani uobičajeni sunčan dan, oblačan i tmuran dan, predveče i veče odabrane lokacije a najviše pažnje će biti posvećeno karakteristikama ovog prostora - arhitekturi, suncu, vodi i brodovima. Lokacija je zbog boja fasada ispunjena toplim tonovima, koji se preslikavaju na vodi, a takođe menja ambijent $\mathrm{u}$ zavisnosti od količine svetla.

\subsection{Arhitektura i istorija lokacije}

Luka Nayhavn ili Nova luka se nalazi u Kopenhagenu u Danskoj. Luku je izgradio kralj Kristijan Peti koji je vladao Danskom i Norveškom u 17.veku. Hteo je da poveže more sa starim centrom grada. Izgrađena je $\mathrm{u}$ periodu od 1670. do 1673. godine i posvećena je švedskim ratnim zarobljenicima iz Dansko-Švedskog rata. Prvobitno je bila komercijalna luka u kojoj su brodovi iz celog sveta pristajali, a kako su okeanski brodovi postajali veći, ona je preuzela unutrašnji teretni saobraćaj malih brodova. Nakon drugog svetskog rata, kopneni saobraćaj je preuzeo teretni transport, a sredinom šezdesetih godina dvadesetog veka je osnovano Nyhavn društvo, sa ciljem revitalizacije ovog područja. Karakteristika ovog prostora jeste arhitektura, konkretno činjenica da je svaka fasada druge boje. Stil u kom su građene kuće je autentčan 
Danski stil iz 17.veka. Najstarija kuća je izgrađena 1681. godine, a korišćeni su drvo i cigle. Najviša spratnost je $\mathrm{P}+4$, a najniža $\mathrm{P}+2$. Danas su sve stare kuće revitalizovane a prizemlja svih objekata su javna i time omogućuju različit i bogat sadržaj posetiocima [1].

\section{PREGLED POSTOJEĆIH METODA POSTAVLJANJA SCENE}

\subsection{Postavljanje geometrije}

Modelovanje arhitektonske scene je moguće uraditi na nekoliko načina. Uobičajeno je da se prvo uvede fajl sa merama i na osnovu njega se modeluje. Druga metoda za rešavanje geometrije, kod koje su zadate mere, jeste modelovanje uz pomoć alata za restituciju perspektivne slike pomoću samo jedne fotografije. Ako ne postoje podaci o merama i veličinama celokupnih objekata kao i njihovih detalja, uz pomoć fotografija se dolazi do potrebnih dimenzija. Takođe, perspektivna projekcija rendera mora da se poklopi sa perspektivom na referentnoj fotografiji. Funkcija restitucije fotografije koja služi za određivanje perspektive scene je uvedena u 3Ds Max 2014, te ukoliko se radi u starijoj verziji, ova opcija ne postoji [2].

\subsection{Podešavanje vode u vizualizaciji}

Posmatrajući odabranu sliku za analizu moguće je primetiti da voda zauzima četvrtinu fotografije, te ona mora biti kvalitetno izmodelovana i mapirana. To se može izvršiti na više razluičitih načina. Jedan od načina dobijanja vode jeste pomoću postavljanja Plane površi i dodavanje i menjanje modifajera Noise. On direktno modifikuje geometriju. Drugi način dobijanja vodene površi u 3DsMax-u je korišćenje dodatka PhoenixFD, koji proračunava dinamiku fluida i najčešće se koristi $u$ animaciji. Treći i četvrti način dobijanja vodene površine su slični. Oba načina koriste tehniku dodavanja mape na geometriju bez prethodnog modelovanja, razlika je ta što jedan koristi standardnu Displace mapu a drugi vektorsku.

\subsection{Ugao posmatranja i postavljanje kamere}

Odabir ugla posmatranja je jedna od osnovnih, možda najtežih, ali i najbitnijih stvari prilikom pravljenja fotografija i renderovanja. Od toga zavisi šta će biti prikazano. Proces pravljenja rendera počinje postavljanjem kamere. Bitno je izabrati ugao kamere koji jasno prikazuje subjekat i da je estetski prihvatljiv. Da bi se dobio kvalitetan pogled, bitno je prvo odrediti šta treba da se predstavi i onda pozicionirati kameru da na taj način uhvati željeni kadar. U scenu je moguće ubaciti više kamera iz različitih uglova i lako se može prebaciti iz jednog pogleda u drugi. Kada se podesi ugao posmatranja, odnosno fizički položaj kamere, potrebno je uzeti u obzir i osnovne principe kompozicije. Bitno je obratiti pažnju i na međusobnu poziciju svetla i kamere, jer je najbolje pozicionirati kameru u bilo kom pravcu od $90^{\circ} \mathrm{u}$ odnosu na pravac osvetljenja, a najbolje je da osa kamere i pravac osvetljenja grade ugao od $45^{\circ}$. Osim položaja, kamera omogućava da se kontroliše i osvetljenost rendera, količinu svetla koju će ona primiti, tako da se dobije svetliji ili tamniji render u celini [3].

\subsection{Pozicioniranje i podešavanje svetla $i$ materijala}

Nakon postavljanja geometrije potrebno je popuniti scenu svim potrebnim osvetljenjem i izvršiti materijalizaciju svih objekata. Pre toga, međutim, potrebno je odabrati Render Engine koji obavlja sve kalkulacije vezane za svetlo, materijale i njihove karakteristike, a kao rezultat daje gotov render. Bez obzira na odabir render engine- $a$, potrebno je postaviti osvetljenje i materijale koji su kompatibilni sa istim. U ovom radu će se koristiti VRay za potrebe izrade rendera zbog mogućnosti finog podešavanja svakog aspekta njegove operacije. Sva svetla i materijali koji će biti analizirani pripadaju VRay dodatku.

\subsubsection{Podešavanje svetla}

Osvetljenje, pored 3D modela, predstavlja jedan od najvažnijih elemenata svake scene. Svetlo u VRay-u može menjati intenzitet, boju i tip izvora. Može biti pravougaono, u obliku diska, sferično, Mesh, Dome, IES, AmbientLight, i Sun. Za svaku scenu postavljeno je drugačije svetlo, sa drugačijim intenzitetom i položajem u zavisnosti od potrebe. Svetlo koje je dominantno u renderima svih tipova jeste Dome. To je sferičan tip osvetljenja koji za razliku od običnog sferičnog svetla sija ka unutrašnjosti sfere, imitirajući nebeski svod, obasjavajući celu scenu difuznim svetlom [4]. Svetlo na koje je potrebno obratiti posebnu pažnju u ovom radu je Sun, zbog toga što ono formira senke koje najviše doprinose realizmu. Važan parametar kod podešavanja ovog tipa osvetljenja je njegova pozicija u sceni jer ima direktan uticaj na promenu boje materijala, na pravac $\mathrm{i}$ veličinu senke. VRay Sky je prateći element ovom tipu osvetljenja, jer u skladu sa pozicijom Sun-a menja boju neba. Ova dva elementa utiču na sve objekte u sceni na način na koji pravo Sunce utiče na realne objekte. Uz postavljanje ova dva svetla većina scena čija je tema eksterijer je kompletirana i moguće je preći na postavljanje materijala.

\subsubsection{Materijalizacija u vizualizaciji}

Posmatrajući referentne fotografije, mogu se napraviti tri grupe materijala koje su zastupljene. Transparentni, nisko detaljni i visoko detaljni materijali. Transparentni materijali su oni koji propuštaju određenu količinu svetla, a najčešće su visoko refleksivni. Druga vrsta materijala koji se pojavljuju su nisko detaljni materijali koji koriste samo Diffuse boju i Dirt mapu. Takvi materijali mogu biti napravljeni samo podešavanjem boje, jer su objekti koji imaju ovakav materijal dovoljno udaljeni, tako da se tekstura materijala ne vidi. Treća vrsta materijala koja se koristi su materijali sa dodatnim Bump i Displace mapama. Bump mapa simulira neravnine materijala $\mathrm{i}$ njenim uvođenjem materijal izgleda kao da je reljefan iako geometrija ostaje nepromenjena. Zato je, pored Bump mape, moguće ubaciti i Displace mapu koja deformiše geometriju. Ona se uvozi isključivo za objekte koji se nalaze u prvom planu, zbog toga što drastično povećava detaljnost obrade površine ali i količinu vremena potrebnog za render. Zbog ova dva razloga treba izbegavati postavljanje ove mape na udaljene objekte. [5] 


\section{POSTAVLJANJE SCENE}

\subsection{Postavljanje geometrije}

Izabrane fotografije imaju određene karakteristike koje su interesantne za ovo istraživanje, odnosno mogu bolje prikazati odgovor na problem koji se javlja kod postavljanja geometrije na osnovu samo jedne fotografije. Naime, jedna od prvih karakteristika fotografije koja je jasno uočljiva je perspektivna projekcija. Međutim, detaljnija analiza otkriva da ne postoji dovoljan broj linija koje služe kao odrednice za tačku nedogleda. Razlozi za to su starost objekata i efekat gužve. Objekti na lokaciji su građeni od 17. veka, tako da su pretrpeli uticaje sleganja i deformacije elemenata. To otežava nalaženje pravih linija. Druga karakteristika koja je ključna za rešavanje geometrije je određeni aspekt arhitekture ove lokacije, a to je pravilo koje diktira da ne smeju postojati dva ista tona na uzastopnim objektima. Boja svakog objekta je drugačija, pa je zbog toga bilo lako razjasniti gde se nalazi granica između njih. Boja venaca, prozora, krovova i slično je dalje različita u odnosu na svaku fasadu, što je pomoglo u raspoznavanju elemenata. Prvi korak ka postavljanju dobre scene, na osnovu referentne fotografije je aproksimacija perspektive.

$\mathrm{Za}$ to je moguće koristiti bilo koji alat za obradu fotografija. Iscrtan je veliki broj linija kako bi se odredila tačka nedogleda iz njihovih tačaka preseka. Sledeći zadatak je iskoristiti nove informacije dobijene iz prethodnog postupka, tako što se obrađena fotografija uvozi u 3 ds Max. Uz njenu pomoć se vrši Perspective Match i određuje pozicija kamere. Treba podesiti rezoluciju rendera da odgovara dimenzijama fotografije, da dobijena geometrija ne bi bila deformisana. Potrebno je uzeti neku odrednicu na fotografiji i pretpostaviti da je kota koja određuje njenu visinu u odnosu na druge elemente nula. Na toj visini se postavlja kubus bilo kojih dimenzija, koja služi za definisanje pozicije objekta od kog je moguće započeti modelovanje. Razlog za postavljanje kubusa je mogućnost ravnanja njenih stranica sa svim osama perspektive istovremeno. U ovom slučaju kubus se postavlja na mesto najbližeg objekta zbog najbolje preciznosti, a za površ koja je na nultoj visini uzet je dok. Tako se može odrediti tačna udaljenost objekta od kamere i njegova veličina. Nakon što je kubus postavljen na odgovarajuće mesto, njegove dimenzije se prilagođavaju dimenzijama objekta na fotografiji. Ukoliko su dimenzije uspešno usklađene, modelovanje se nastavlja dodavanjem novih kutija koje se ređaju uzastopno u uglovima fasada, a omogućeno je time što su u ovom slučaju, na referentnoj fotografiji, u pitanju kuće u nizu. Sleduje prvi stepen modelovanja kubusa - pravljenje krovova. Drugi stepen fine modifikacije podrazumeva dobijanje otvora na fasadama. Treba naglasiti da se postupak mora ponoviti za svaki objekat posebno. Tokom čitavog procesa izvođenja ovih nivoa detaljnosti, bitno je koristiti pogled iz kamere. Razlog za to je perspektivna projekcija koja je postavljena u odnosu na fotografiju, pa se jedino iz tog ugla mogu videti pravilne dimenzije objekata. Ostatak geometrije, brodovi, urbani mobilijar i ostali elementi koji služe svrsi postizanja efekta gužve, su modelovani odvojeno i dodati u scenu sa ili bez modifikacija.

\subsection{Podešavanje vode}

U ovom radu je voda bitan element, zbog toga što zauzima oko jednu četvrtinu fotografije. Razrađene metode za njenu izradu već postoje. Zbog toga neće biti detaljnije pokriven postupak izrade. Postavljanje uključuje korišćenje Plane- $a$ sa visokim brojem podela na koji je dodat Noise modifier. Zatim je menjana isključivo njegova veličina, kako bi se dobila drugačija voda, u zavisnosti od atmosfere, na svakoj fotografiji.

\subsection{Podešavanje svetla}

Svetla koja su korišćena u ovom radu su Sun i Dome, sa VRaySky kao pratećim elementom. Izuzetak je noćni render koji sadrži tačkasta osvetljenja koja imitiraju lampe i ulično osvetljenje. Svetlo Sun je postavljeno u odnosu na strane sveta. Iz opisa lokacije je poznato kako je orijentisan model. Pošto su odnosi sa fotografije ispoštovani, moguće je pokazati promenu ambijenta samo uz pomeranje položaja svetla Sun. Najbolji način za proveru je izvođenje takozvanih Clay rendera, rendera bez materijala. Na njima je lako utvrditi da li je položaj senke na odgovarajućem mestu.

\subsection{Podešavanje materijala}

Materijalizacija predstavlja poslednji korak ka cilju postizanja realističnih rendera. Kriterijumi koji utiču na taj realizam su detaljnost materijala i kvalitet korišćenih mapa. Koristeći granicu detaljnosti, može se opisati struktura pojedinih materijala koji su upotrebljeni. Zastupljeni materijali spadaju u prethodno navedene grupe: transparentni - staklo na prozorima i drugim otvorima na fasadi, staklo na elementima urbanog mobilijara i voda; materijali niske detaljnosti - skup materijala koji se nalazi iza granice detaljnosti u koji spadaju materijali koji su sačinjeni samo od osnovne boje i jedne mape, Dirt; materijali visoke detaljnosti - svi ostali materijali prisutni na sceni u čiji sastav ulaze Diffuse mape, refleksija, Dirt i Bump. Izuzetak čine oni materijali koji su u grupi visoke detaljnosti ali, pored navedenih, sadrže dodatno Displace mapu. Oni se na ovom radu, nalaze isključivo na objektima koji su u prvom planu, kako bi povećali nivo realnosti.

\subsection{Rezultati}

Uzevši u obzir da su fotografije koje su korišćene kao referentne, obrađene u postprodukciji, postizanje jednakog nivoa realzma zahteva jednak nivo obrade dobijenih rendera.

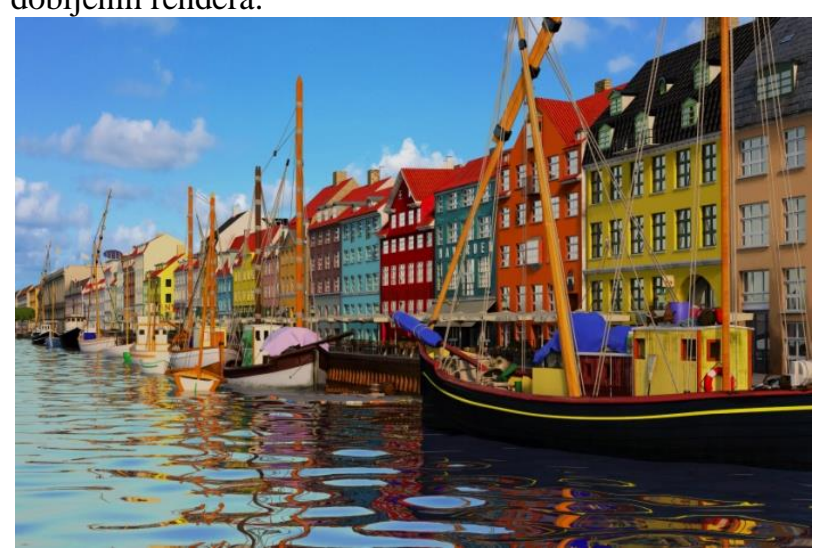

Slika 1. Prikaz rešenja rendera - doba dana- oko podneva 


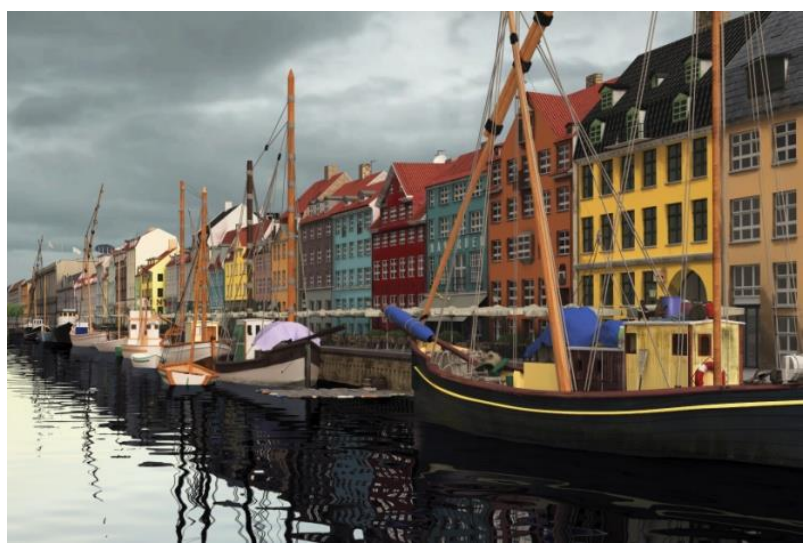

Slika 2. Prikaz rešenja rendera - doba dana- oblačan dan

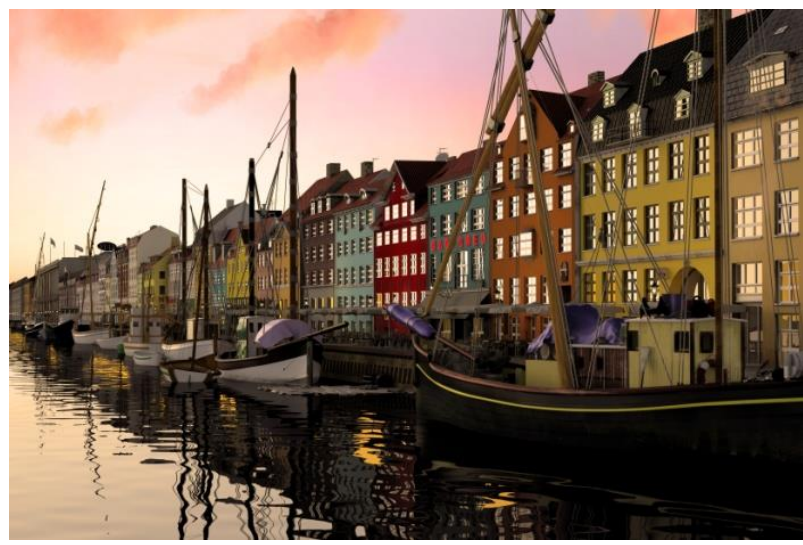

Slika 3. Prikaz rešenja rendera - doba dana- predveče

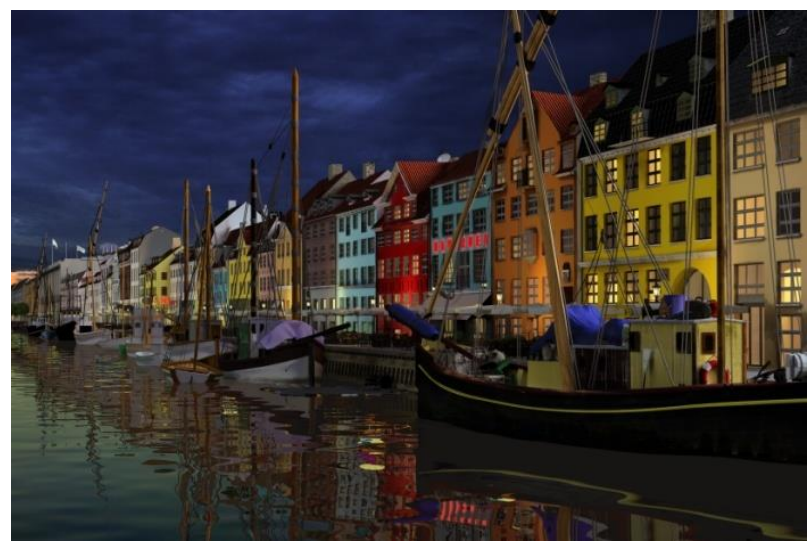

Slika 4. Prikaz rešenja rendera - doba dana- noć

\section{DISKUSIJA I ZAKLJUČAK}

Prilikom postavljanja svakog elementa scene potrebno je zauzeti kritički stav pri razmatranju opcija za njegovo izvođenje. Prednosti i mane pojedinih postupaka utiču na izbor metode izrade. Kada se radi arhitektonska vizualizacija u odnosu na fotografije, kao što je već napomenuto, moguće je pristupiti rešavanju geometrije na dva načina. To može biti uz pomoć samo jedne ili više njih, iz različitih uglova. Ukoliko je vreme od presudnog značaja koristi se prva metoda, dok druga postiže precizniji rezultat zbog mogućnosti detaljnijeg analiziranja svakog dela objekta. Istraživanje pokazuje da je samo jedna fotografija dovoljna za postavljanje geometrije tako da se na render prenese ambijent sa slike. Voda ima veliki uticaj na ambijentalnost prostora, pa zbog toga mora biti pažnjivo modelovana. Tehnika promene same geometrije, u odnosu na druge tehnike, omogućava veći stepen kontrole njenog izgleda. Postavljanje svetla zahteva fina podešavanja velike količine parametara vezanih za njega, a svodi se na ispitivanja i testiranja na Clay renderima. Poznavanje lokacije i ponašanja svetla na istoj, kao i tačna geometrija, u velikoj meri pomaže kod postavljanja pravilnog osvetljenja i pozicije senke. Prilikom arhitektonske vizualizacije materijalizacija predstavlja poslednji korak. Kvalitetne mape, odnosno dobro izabrana tekstura, višestruko uvećava nivo realizma rendera, a bitno je postići i egzaktan ton svih objekata $u$ okviru scene. Pored svih prethodno navedenih elemenata koji čine scenu, efekat gužve, odnosno dodavanje ambijentalnih i drugih sitnih detalja, iako teško vidljivih, u velikoj meri doprinosi realizmu. To se odnosi naročito na objekte u prvom planu. Prilikom izrade ovog rada, zaključeno je da nije moguće preterati sa efektom gužve, da detalji doprinose realnije prikazu prostora. Bitno je obratiti pažnju da svi objekti budu tematski. Rezultat ovog rada je realistična vizualizacija prostora eksterijera urbanog područja u četiri ambijenta, sa karakterističnom arhitekturom, vodom i efektom gužve.

\section{LITERATURA}

[1] G.Jan, G.Lars (1966). Public spaces, Public life, Copenhagen, The Danish Architectural Press and the Royal Danish Academy of Fine Arts

[2] Autodesk (2017). Dostupno na :

https://knowledge.autodesk.com/support/3ds-max/learnexplore/caas/CloudHelp/cloudhelp/2018/ENU/3DSMaxRendering/files/GUID-CA74469E-9320-4801-B3F0B4E00461689C-htm.html [poslednji pristup: 19.10.2017]

[3] Bekerman (2014). Dostupno na :

https://www.ronenbekerman.com/photographic-approachin-architectural-

visualisation/\#Introduction_to_Photographic_Approach_i n_Architectural_Visualization

[poslednji pristup: 19.10.2018]

[4] Chaosgrup (2018). Dostupno na :

https://docs.chaosgroup.com/display/VRAY3MAX/Light s [poslednji pristup: 19.10.2017]

[5] Chaosgrup (2018). Dostupno na :

https://docs.chaosgroup.com/display/VRAY3MAX/Mater ials [poslednji pristup: 19.10.2017]

\section{Kratka biografija:}

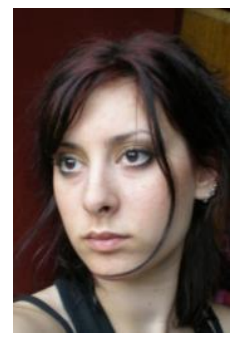

Iva Sučević,

rođena je u Beogradu 1991. god. Master rad na Fakultetu tehničkih nauka iz oblasti -Vizualizacija urbanog područja - Studija slučaja Nova luka u Kopenhagenu. 